\title{
Analysis of Thin Thermal Oxides on (0001) SiC Epitaxial Layers
}

\section{Conference Paper}

Author(s):

Woerle, Judith (D); Camarda, Massimo; Schneider, Christof W.; Sigg, Hans; Grossner, Ulrike (D); Gobrecht, Jens

Publication date:

2016-05-15

Permanent link:

https://doi.org/10.3929/ethz-b-000225382

Rights / license:

In Copyright - Non-Commercial Use Permitted

Originally published in:

Materials Science Forum 897, https://doi.org/10.4028/www.scientific.net/msf.897.119 


\section{Analysis of thin thermal oxides on (0001) SiC epitaxial layers Judith Woerle ${ }^{1,2, a^{*}}$, Massimo Camarda ${ }^{1, b}$, Christof W. Schneider ${ }^{1, c}$, Hans Sigg $^{1, d}$, Ulrike Grossner $^{2, \mathrm{e}}$ and Jens Gobrecht ${ }^{1, \mathrm{f}}$ \\ ${ }^{1}$ Paul Scherrer Institut, 5232 Villigen, Switzerland \\ ${ }^{2}$ Advanced Power Semiconductor Laboratory, ETH Zurich, Physikstrasse 3, 8092 Zurich, Switzerland}

ajudith.woerle@psi.ch, ${ }^{b}$ massimo.camarda@psi.ch, ${ }^{c}$ christof.schneider@psi.ch, dhans.sigg@psi.ch, eulrike.grossner@ethz.ch, jens.gobrecht@psi.ch,

Keywords: Silicon Carbide, thermal oxidation, density of interface states, conductance;

Abstract. In this study, electrical properties of MOS capacitors with varying oxide thicknesses have been investigated. The oxide growth was performed at $1050^{\circ} \mathrm{C}$ without any further post-oxidation annealing steps resulting in oxide thicknesses between $2 \mathrm{~nm}$ and $32 \mathrm{~nm}$. Capacitance-Voltage measurements revealed a decreasing density of interface defects for increasing oxide thickness suggesting a deterioration of the interface at the initial stage of the growth.

\section{Introduction}

Although Silicon Carbide (SiC) represents the most mature material for wide-bandgap high-voltage power electronic devices, the inversion channel of $\mathrm{SiC}$ metal-oxide-semiconductor field effect transistors (MOSFETs) is still strongly affected by low mobility and low performance reliability. These problems are related to the large amount of both interface defects and near-interface traps generated during thermal oxidation.

In early literature, it was suggested that during oxidation, especially for thick oxides, a high density of interface states $\left(D_{\mathrm{it}}\right)$ could occur due to carbon accumulation at the interface [1]. A deterioration of the interface with increasing thickness, in this case in the range of $d_{\mathrm{Ox}}=5-75 \mathrm{~nm}$, was later reported in [2]. More recently, R.H. Kikuchi et al. [3] suggested an ideal process window in terms of oxidation temperature with $T=1100-1300{ }^{\circ} \mathrm{C}$, but a deterioration of the interface would occur not just during later stages of the oxidation process but already during the temperature ramp-up when the chamber is not within the suggested temperature range. The group succeeded in minimizing oxidation by-products of thin $(\sim 15 \mathrm{~nm})$ oxides by using a rapid thermal process (with ramp rates up to $\left.600{ }^{\circ} \mathrm{C} / \mathrm{min}\right)$ obtaining close-to-ideal interfaces $\left(D_{\mathrm{it}} \sim 10^{11} \mathrm{eV}^{-1} \mathrm{~cm}^{-2}\right)$ without further post-oxidation annealing (POA) processes. Here, instead of using high ramp rates, the time of the oxide growth at the plateau temperature of $1050^{\circ} \mathrm{C}$ is increased in order to make the influence of the ramping comparably short.

\section{Experiment}

For this study, $10 \times 10 \mathrm{~mm}$ pieces of the same $4^{\circ}$ off-oriented n-type $4 \mathrm{H}-\mathrm{SiC} \mathrm{Si}(0001)$ face substrates (CREE) have been processed. The effective carrier density and thickness of the epitaxial layer were $4 \times 10^{15} \mathrm{~cm}^{-3}$ and $15 \mu \mathrm{m}$, respectively. Prior to thermal oxidation, all samples were cleaned in a heated Caro's acid for 10 minutes and dipped in HF (10\%) for 2 minutes.

The samples were loaded into the oxidation furnace immediately after the cleaning and dry oxidation was performed at $1050{ }^{\circ} \mathrm{C}$ with an $\mathrm{O}_{2}$ gas flow of 11 SLPM and a ramp-up and rampdown in $\mathrm{N}_{2}$ with a ramp rate of $10 \mathrm{~K} / \mathrm{min}$.

One sample (referred to as " 0 min oxidation") did not receive an oxidation step in $\mathrm{O}_{2}$ but was ramped up and down in $\mathrm{N}_{2}$ atmosphere without an oxidation step in-between. The obtained oxide thicknesses, ranging from $d_{\mathrm{Ox}}=2 \mathrm{~nm}$ to $d_{\mathrm{Ox}}=32 \mathrm{~nm}$, were determined ex-situ by both capacitancevoltage $(\mathrm{CV})$ and grazing incidence $\mathrm{X}$-ray reflectivity (XRR) measurements. 
Note that although the formation of a native oxide layer of up to $10 \AA$ has been observed after a wet cleaning process [4], we did not find any indication of native oxide after our cleaning step neither by XPS nor CV measurements.
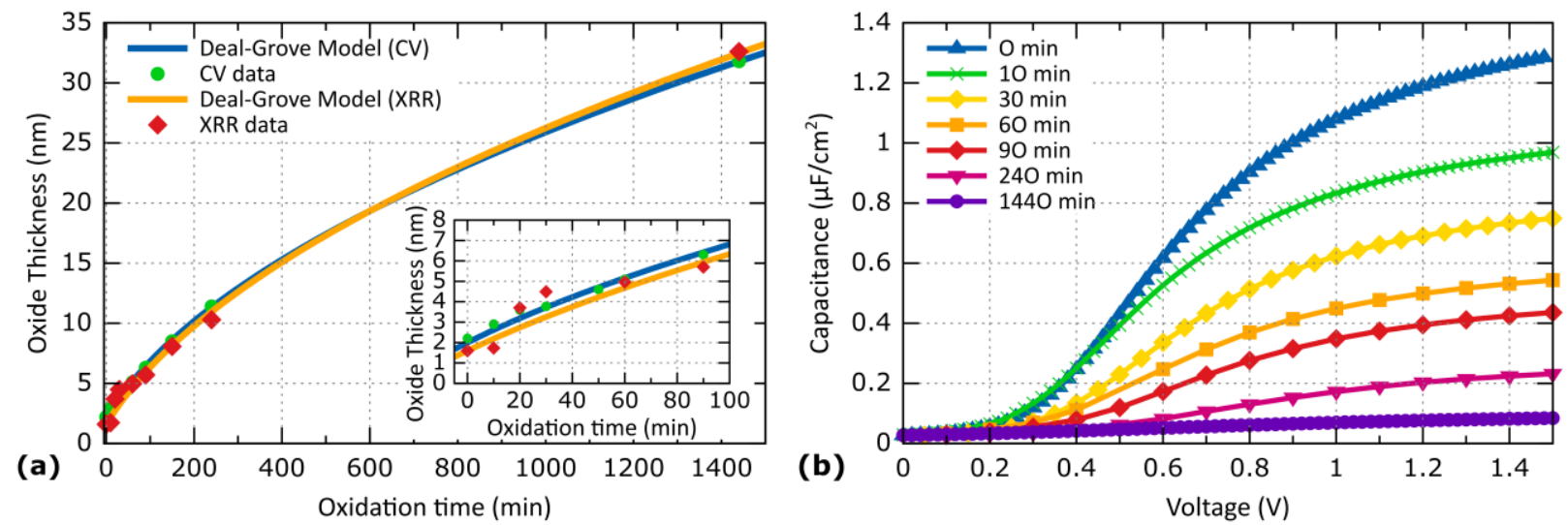

Fig. 1: (a) Extracted oxide thicknesses from the CV data and comparison with XRR data. The inset is a zoom of the first $100 \mathrm{~min}$ of oxidation. (b) Capacitance-voltage analysis at $1 \mathrm{MHz}$.

MOS devices were fabricated by depositing $500 \mathrm{~nm} \mathrm{Al}$ on the oxide and $100 \mathrm{~nm} \mathrm{Ni}$ on the substrate. The MOS capacitors with radii of $200 \mu \mathrm{m}$ and $300 \mu \mathrm{m}$ were analyzed by high-frequency ( $1 \mathrm{MHz}$ ) CV measurements to obtain the $\mathrm{SiO}_{2}$ oxide thickness and the interface state density $D_{\text {it }}$. Current-voltage (IV) measurements were conducted to determine the leakage current through the oxides. All measurements were conducted at room temperature and repeated on 10 devices to assess the device-to-device variability.

In addition to the MOS capacitors, lateral n-channel MOSFETs have been fabricated on $4^{\circ}$ offoriented n-type $4 \mathrm{H}$-SiC $\mathrm{Si}(0001)$ face wafers, with epitaxial p-type $\mathrm{SiC}\left(15 \mathrm{x} 10^{15} \mathrm{~cm}^{-3}\right)$ as the channel region. Source and drain (S/D) N+ regions were formed by implantation with phosphorous, followed by high-temperature activation. The cleaning prior to the oxidation and the oxide growth at $1050^{\circ} \mathrm{C}$ for $1440 \mathrm{~min}$ were done as described above, resulting in an oxide thickness of $d_{\mathrm{Ox}}=32$ nm.

For the gate contact, $100 \mathrm{~nm} \mathrm{Ni}$ was deposited using e-beam evaporation. After a wet-etch for the gate definition and a dry-etch process for opening the oxide below the $\mathrm{S} / \mathrm{D}$ region, $100 \mathrm{~nm} \mathrm{Ni}$ were deposited for the S/D contacts. A final rapid thermal anneal $\left(1000^{\circ} \mathrm{C}\right.$ in forming gas) was performed to decrease the contact resistance of source and drain. All nMOSFET devices had gate channel areas of $100 \mu \mathrm{m} \times 180 \mu \mathrm{m}$ and similarly sized gate and S/D contact pads. Field effect mobilities of the MOSFET devices were then obtained by transconductance measurements.

\section{Results and Discussion}

Fig. 1(a) shows the obtained oxide thickness for different oxidation times, extracted both via XRR measurements and CV measurements (Fig. 1(b)). From the electrical analysis, assuming an ideal dielectric constant of $\varepsilon_{\mathrm{r}, \text { eff }}=3.9$ and using the McNutt-Sah method [5] to compensate for leakage currents, the different oxide thicknesses can be extracted. A systematic overestimation of $d_{\mathrm{Ox}}$ from the CV data is consistent with what was found in Ref. [6] and indicates a lower real effective oxide dielectric constant of $\varepsilon_{\mathrm{r}, \mathrm{eff}} \sim 3.66$.

We also fitted both data using the Deal-Grove model, obtaining the following fitted parameters $\left(\mathrm{CV}: \mathrm{B}=58.8 \mathrm{~nm}^{2} / \mathrm{hr}, \mathrm{B} / \mathrm{A}=3.72 \mathrm{~nm} / \mathrm{hr}\right.$; XRR: B $=54.3 \mathrm{~nm}^{2} / \mathrm{hr}, \mathrm{B} / \mathrm{A}=3.69 \mathrm{~nm} / \mathrm{hr}$ ) for the $\mathrm{CV}$ and XRR data, respectively.

The IV characteristics for MOS capacitors with different $d_{o x}$ are shown in Fig. 2. While very thin oxides ( $0 \mathrm{~min}-30 \mathrm{~min})$ are dominated by direct tunneling current [7], thicker ones are dominated by Fowler-Nordheim tunneling [8] with an extracted barrier height of $\Phi_{\mathrm{B}, \exp }=2.84 \mathrm{eV}$ (close to the ideal value of $\Phi_{\mathrm{B}, \text { theory }}=2.7 \mathrm{eV}$ ). 


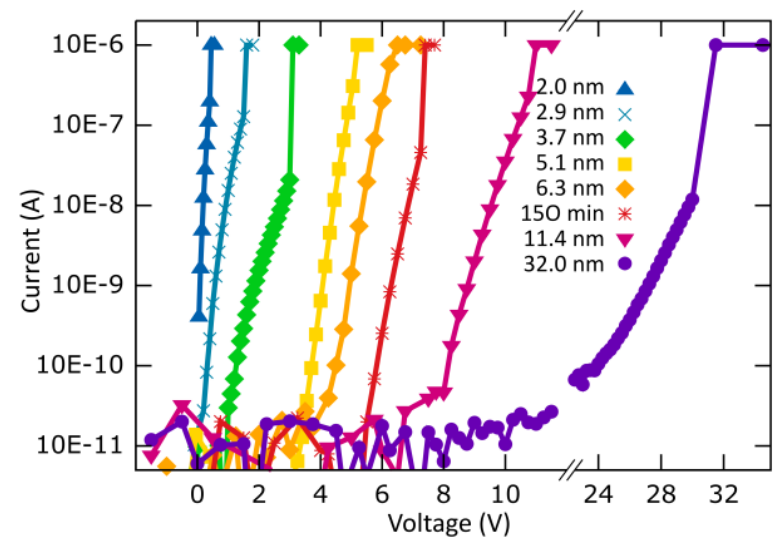

Fig. 2: DC current-voltage curves to determine the leakage current at the flatband for the different oxidation processes.

Fig. 3(a) shows the conductance-voltage $\left(G_{\mathrm{p}}-V\right)$ curve measured at a frequency of $1 \mathrm{MHz}$ for each oxide thickness. The density of interface states $D_{\mathrm{it}}$ is determined by the relation [9]:

$$
D_{\mathrm{it}}=\left.\frac{1}{q A f} \frac{G_{p}}{\omega}\right|_{\max },
$$

where $\omega$ is the frequency of the measurement, $A$ is the area of the MOS contact and $f$ is a parameter that depends on the fluctuation of the surface potential.
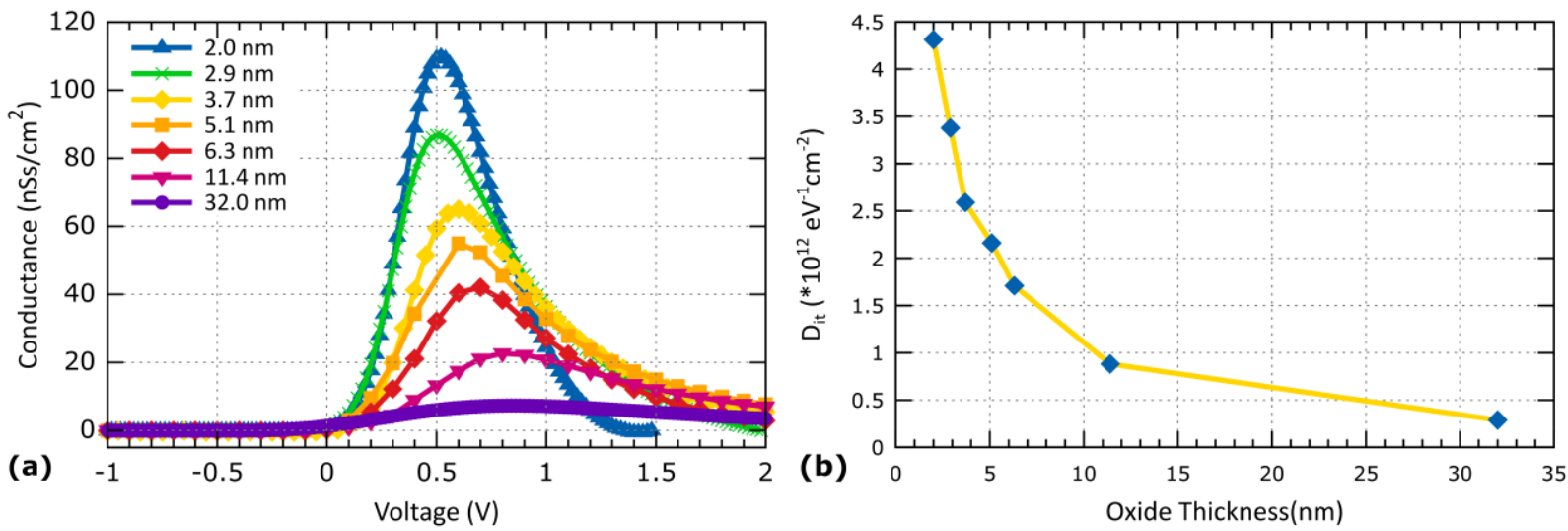

Fig. 3: (a) $G_{\mathrm{p}^{-}} V$ data at $1 \mathrm{MHz}$. (b) Density of interface state traps extracted from $G_{\mathrm{p}^{-}} V$ data.

From the conductance peaks, $D_{\text {it }}$ values were determined for all MOS capacitors and are given in Fig. 3(b) as function of oxide thickness. The strong decrease of the interface state density for increasing oxidation times supports the hypothesis of an interface degradation during the initial stage of the oxidation process and is in good agreement with Ref. [3]. In fact, the sample which was only exposed to the heating-up and cooling-down in $\mathrm{N}_{2}$, without an oxidation step in-between, shows the highest measured $D_{\text {it }}$, thus supporting the idea of a degradation of the interface during the ramping of the chamber.

In addition, lateral nMOSFETs with a thermally grown oxide of $d_{\mathrm{Ox}}=32 \mathrm{~nm}\left(1440 \mathrm{~min}, 1050^{\circ} \mathrm{C}\right)$ were electrically characterized to see whether the low defect density at the interface is consistent with a high mobility. Fig. 4(a) shows the transfer characteristics $\left(I_{D^{-}} V_{\mathrm{G}}\right)$ of the MOSFETs taken in the linear region at a drain voltage of $V_{\mathrm{DS}}=0.5 \mathrm{~V}$. From these measurements, the field effect mobility $\mu_{\mathrm{FE}}$ was determined using [10]:

$$
\mu_{\mathrm{FE}}\left(\mathrm{V}_{\mathrm{G}}\right)=\frac{L}{C_{\mathrm{Ox}} W V_{\mathrm{DS}}} g_{\mathrm{M}}\left(\mathrm{V}_{\mathrm{G}}\right)
$$

where $g_{\mathrm{M}}$ is the transconductance, $L$ and $W$ are the channel length and width and $C_{\mathrm{Ox}}$ is the gate capacitance per unit area. The extracted mobility is plotted in Fig. 4(b) with peak mobilities of $\mu_{\mathrm{FE}} \approx$ $35 \mathrm{~cm}^{2} \mathrm{~V}^{-1} \mathrm{~s}^{-1}$ which is consistent with the low $D_{\text {it }}$ measured for MOS capacitors with the same oxide 
thickness. The fairly high mobility is an encouraging result for a thermal oxidation process without any further post-oxidation anneal and shows a favorable improvement to earlier reported channel mobilities of similarly fabricated devices [11].
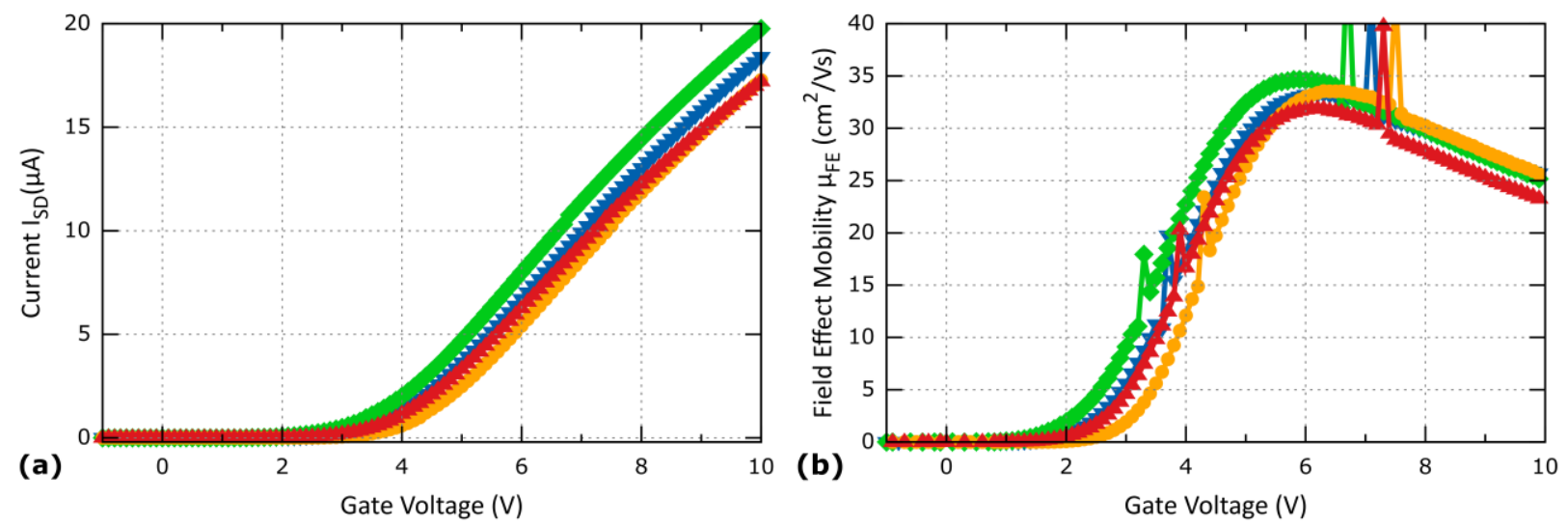

Fig. 4: (a) Drain current $\left(I_{\mathrm{SD}}\right)$ as a function of gate bias for four randomly selected lateral n-type MOSFETs with a 32nm-thick oxide, measured for several devices. (b) Field effect mobility $\mu_{\mathrm{FE}}$ as a function of the gate voltage determined by the MOSFETs' transfer characteristics.

\section{Summary}

In this paper, we compared the electrical characteristics of various MOS capacitors with different oxide thicknesses and showed a reduction of the interface state density for increasing oxide thicknesses down to $D_{\mathrm{it}}=1.1 \times 10^{11} \mathrm{eV}^{-1} \mathrm{~cm}^{-2}$ for $d_{\mathrm{Ox}}=32 \mathrm{~nm}$. For lateral MOSFETs with the same oxide thickness, field effect mobilities of $\mu_{\mathrm{FE}} \approx 35 \mathrm{~cm}^{2} \mathrm{~V}^{-1} \mathrm{~s}^{-1}$ were measured. These results indicate that a low defect density and high mobilities can be achieved by a controlled low temperature thermal oxidation process without further POA steps.

\section{Acknowledgments}

This research project is part of the National Research Programme "Energy Turnaround" (NRP 70) of the Swiss National Science Foundation (SNSF).

\section{References}

[1] V. V. Afanas ev, M. Bassler, G. Pensl, and M. J. Schulz, Phys. Stat. Sol. (a) 162 (1997).

[2] H. Watanabe et al., Applied Physics Letters 99, 021907 (2011).

[3] R. H. Kikuchi and K. Kita, Applied Physics Letters 105, 032106 (2014).

[4] W. Huang et al., Materials Science Forum 778-780, 566 (2014).

[5] D. K. Schroder, in Semiconductor material and device characterization (IEEE Press, 2006).

[6] T. Hosoi et al., Materials Science Forum 740-742, 605 (2013).

[7] B. L. Yang, P. T. Lai, and H. Wong, Microelectronics Reliability 44, 709 (2004).

[8] R. Singh and A. R. Hefner, Solid-State Electronics 48, 1717 (2004).

[9] J. R. Brews, Solid State Electronics 26 (1983).

[10] T. Kimoto and J. A. Cooper, Fundamentals of Silicon Carbide Technology (Wiley, 2014).

[11] F. Roccaforte et al., physica status solidi (a) 211, 2063 (2014). 